\title{
RESEARCH ISSUES UNDERTAKEN WITHIN QUALITY MANAGEMENT - THE OVERVIEW OF SELECTED LITERATURE
}

\author{
ANNA M. OLSZEWSKA
}

\begin{abstract}
A B S T R A C T
Quality is currently a key element in the process of the rivalry where the customer is at stake. Contemporary enterprises undertake several actions aimed at its creation and more effective quality management. This is as well required by the market with enterprises of various character that frequently demand specific solutions. The scientific environment eagerly develops this concept in response to such a prevailing need.

The issue of quality management, despite its long history, remains a dynamically developing research discipline and a scientific consideration. Subsequently, this is a very extensive field which encompasses many issues. Thus, this work mainly focuses on identifying research threads undertaken within quality management in selected periodicals. The article describes the undertaken overview and indicates research threads entailed within the analysed subject matter. Moreover, the resultant list of threads was presented in the form of a knowledge map reflecting their coexistence in specific articles. The methods used while preparing this article constitute an overview of the literature and a network analysis.

The research threads highlighted in the paper indicate, which topics are of interest among researchers in terms of issues related to quality management, while their presentation in the form of a network enables fast and unambiguous access to knowledge within this area. The results of analyses described in the publication may attract the interest of mainly those who scientifically deal with the development of the concept of quality management, as well as enterprises that would wish to get acquainted with current trends in this field.
\end{abstract}

quality, quality management, research issues, knowledge map

DOI: 10.1515/emj-2017-0008
Corresponding author:

Anna M. Olszewska

Bialystok University of Technology, Faculty of Management, Department of Business Informatics, Poland

e-mail: a.olszewska@pb.edu.pl

\section{INTRODUCTION}

The concept "quality" does not have one, unambiguous definition (Gudanowska, 2010; Urban, 2007). This idea has been accompanying humans since the beginning of our existence. Egyptians, Greeks, Romans, andother ancient civilisations considered quality as a symbol of perfection (Elshennawy, 2004). Later, as the society developed, the concept also evolved. As an example, Juran defined it as "fitness for use" (Liepina et al., 2013), Dale, Van der Wiele and Van Iwaarden as "fitness for purpose" (Liepina et al., 2013) again Crosby "as conformance to requirements, not as goodness" (Johnson, 2001). The nowadays meaning is created differently, based on a field of study or business it applies to (Szczepańska, 2013). The sense would vary among managers, medical doc- 
tors, and philosophers (Urban, Czerska, 2016). The diversity of definitions of quality transfers to the disparate perception of its management. Liepina, Lapina, Mazais define Quality Management (QM) as "the process whereby certain operations are performed to ensure the achievement of the objectives and improve the company performance" (Liepina et al., 2013). It is intimated, that this process is made of successive, locked in the cycle of activities, which include: (1) quality planning, (2) quality control, (3) quality assurance, and (4) quality improvement (Standard ISO 9000). Over the years, along with the evolution of the concept of quality and quality management, research threads related to QM have been changing. The changes concerned the number of publications linked to both the quality management and fields, considered in the context of the described issue. In the first part of the publication, the Author described how had the quantity of the publications changed over the last 25 years. Firstly, the overall number of publications was analysed and then it was checked for areas that were developing. In the second part, a detailed analysis was conducted of the term "quality management" that coexisted with other expressions and ideas in 2014-2015 and in the most of 2016. The results were presented with the help of the tool VOSviewer. This software visualises the connections and relations between multi-element data sets. Created maps may take different forms, highlighting different aspects of presented information (Gudanowska, 2015). In this article, the form of the network visualisation has been chosen.

\section{PRELIMINARY ANALYSIS}

As the first step of the analysis, information was collected concerning the quantity of publications referring to quality management in 1997-2016. The Author used two databases: the Web of Science and Scopus. Results have been organised into four types of papers: article, conference paper, book, and a book chapter. The breakdown of the number of publications is presented in Figure 1.

Figure 1 shows that the number of publications related to the notion "quality management" is different in both databases. Significantly more publications were collected in Scopus, compared to the Web of Science. That is also why the Author mostly focused on the further considerations, on the data from a more comprehensive database, i.e. Scopus.

Looking at Figure 1, it is noticeable that for a long period (1995-2005) the number of publications mostly maintained stable at about $1200-1400$ publications per year. Since 2006, a significantly increasing interest in the aspect is to be noted, stopping in 2009, at the level of nearly 4000 publications in that year. It was followed by a clear decrease in interest over the year. However, after a few years, in 2013, the number of publications started to increase again, with its peak in the year 2014. The year 2015 came with another minor decrease in the interest in the problem of quality management. A further downturn occurred in 2016 and should not be taken into consideration because the presented data do not incorporate the

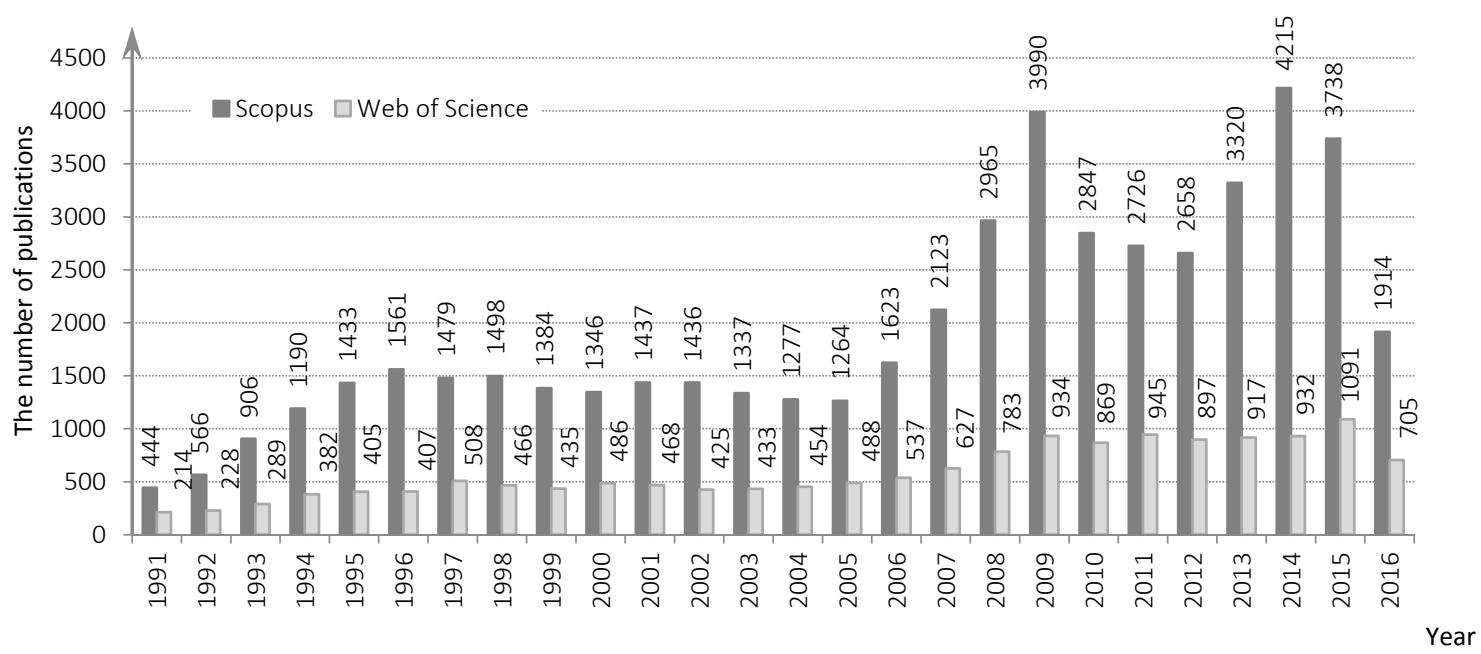

Fig. 1. Number of publications connected with the notion of 'Quality Management' from databases Web of Science and Scopus Source: author's elaboration based on (https://bazy.pb.edu.pl, 27.11.2016). 


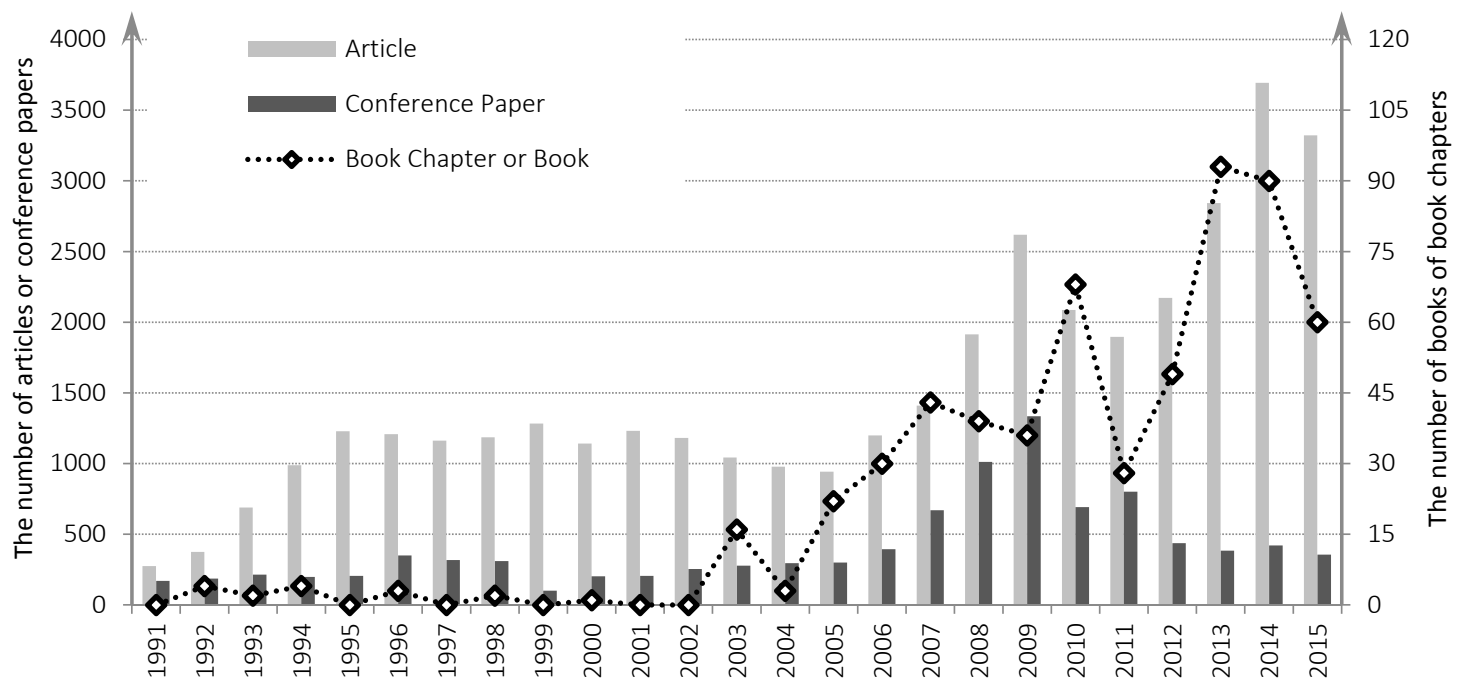

Fig. 2. Number of articles, conference papers, and book chapters or books connected with the notion "Quality Management" from the database Scopus

Source: author's elaboration based on (https://bazy.pb.edu.pl, 27.11.2016).

whole unit of time, as the analysis was conducted based on the data from 27 November 2016.This is the reason behind the exclusion of the year 2016 from further descriptions of this chapter.

The interesting aspect of the presented structure seems to be a specification regarding the type of publication that becomes dominant regarding the term "quality management". The comparison of the number of certain types of publication has been shown in Figure 2.

While analysing Figure 2, it is noticeable, that previously mentioned the significant jump in the interest in quality management in 2006 is also reflected in the articles, as in conference papers. However, after the year 2009 , in the case of the latter, a gradual decrease is observable. It can be concluded that after that year, the topic of quality management stopped being a popular issue discussed at conferences, plateauing in 2012 at about 300-400 publications per year. Nonetheless, in the case of articles, books, and book chapters, the interest in quality management, despite the initial decline after the year 2009, experienced an increase in years 2013-2014. After this period, a minor decrease of the above-mentioned papers is noticeable. To identify the source of several changes in the number of publications related to quality management, the investigation of the fields that used the term quality management was made in the next step. Two analyses were concluded in relation to this criterion, the first of which involved creating a diagram (Figure 3), in which the prevalence of the notion of "quality management" in certain fields of knowledge was expressed through the size of text.
Fig. 3. Fields of publications related to the notion "Quality Management" from the database Scopus

Source: author's elaboration based on (https://bazy.pb.edu.pl, 27.11.2016).
Mathematios Economics. Econometrics and Finonce Material Science Computer Science Agricultural and Biological Sciences Health Professions Nursing Earth and Planetary Sciences Physics and Astronomy

Environmental Science Decision Science Business, Management and Accounting Biochemistry, Genetics and Molecular Biology Social Sciences Pharmacology, Toxicology and Pharmaceutics

By analysing Figure 3, it can be concluded that the term has been mainly appearing in publications related to the field of Medicine during the analysed period. Significantly less frequently but still somewhat often, it appeared in the field of Engineering. The other areas, in which issues connected with quality management have been described were Business, Management and Accounting, Computer Science, 


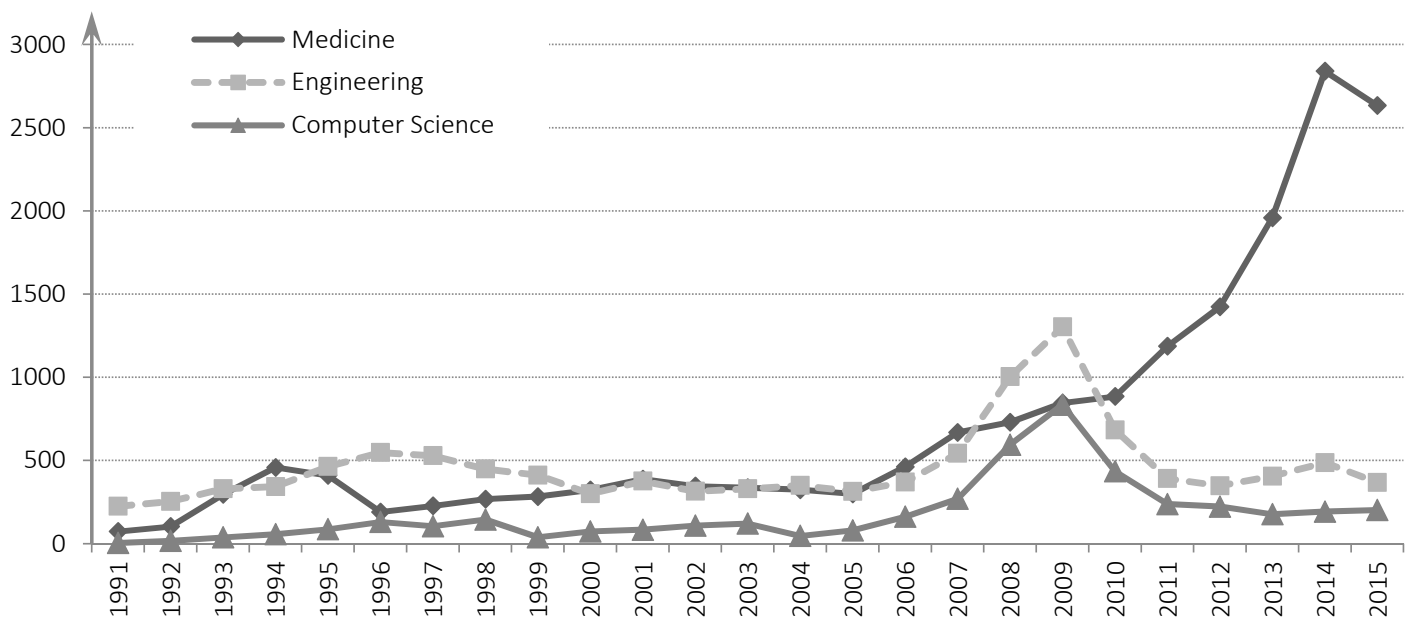

Fig. 4. Number of publications connected with the notion "Quality Management" in areas of Medicine, Engineering and Computer Science from the database Scopus

Source: author's elaboration based on (https://bazy.pb.edu.pl, 27.11.2016).

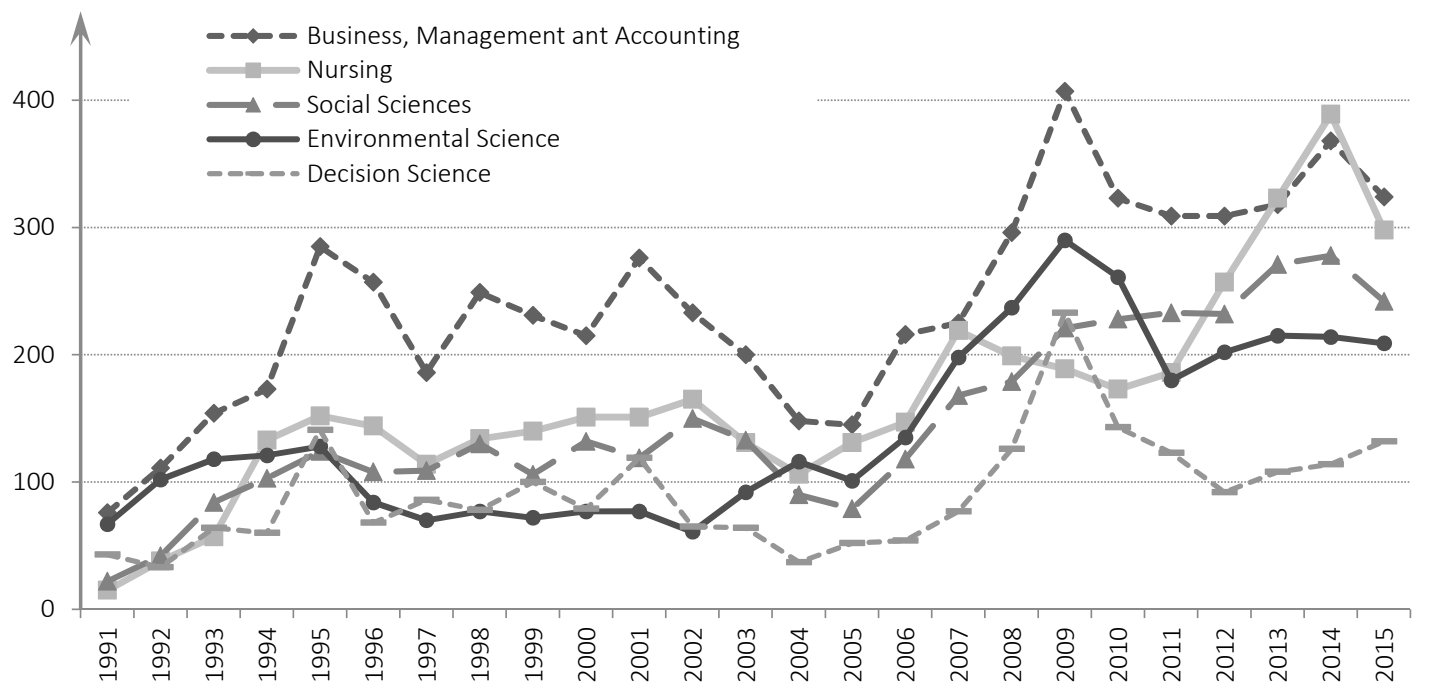

Fig. 5. Number of publications connected with the notion "Quality Management" in areas of Business, Management and Accounting, Nursing, Social Sciences and Environmental Science from the database Scopus

Source: author's elaboration based on (https://bazy.pb.edu.pl, 27.11.2016).

Nursing, Social Sciences, Environmental Science and Decision Science. The remaining fields occurred much less frequently.

Chosen and mentioned above fields, i.e. those, in which publications related to quality management appeared most frequently, have been analysed for changes in the number of publications in the following years. The goal of this analysis was to show areas, on which the subject of quality management was mainly focused during the analysed period. Changes in the number of publications related to quality management and connected with the fields mentioned above in1991-2015 were presented in the graphs in Figures 4 and 5.

While analysing Figures 4 and 5, it is noticeable, that issues related to quality management, described in publications from the fields of Medicine and Nursing indicate the clear upward trend appearing in 2005-2014, which significantly increased in 2011. Only in 2015, the number of publications connected with the described term from the areas of Medicine and Nursing has slightly decreased. The situation looks similar when it comes to the field of Social Sciences; however, in this case, it is noticeable that the 


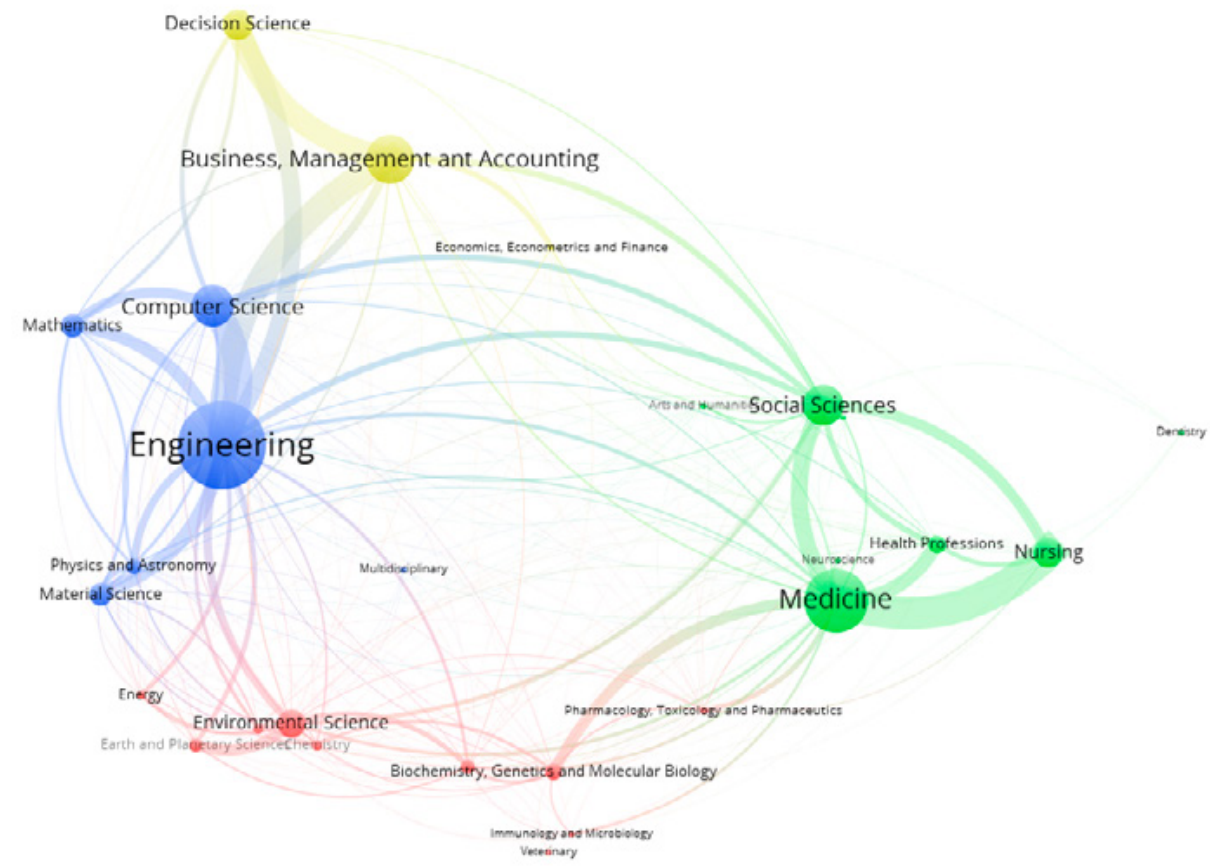

Fig. 6. Map presenting the co-occurrence of areas connected with publications related to the scope of quality management in 1991-2016 Source: author's elaboration based on (https://bazy.pb.edu.pl, 27.11.2016) using VoSviewer.

increase is more rapid at the beginning, and slowing faster at the end. When it comes to the fields of Engineering, Computer Science, and Decision Science, a significant jump in the interest in the issues of quality management was noted in 2009. After that, the number of publications decreased sharply. A similar peak can also be observed in the area of Environmental Science; however, here since the year 2011, the number of publications related to quality management has practically remained static. It should also be noted that the subject of quality management was still present, despite temporary decreases in areas of Business, Management and Accounting.

Summarising the above, it is worth mentioning that the issue of quality management, despite the fact of it not being a trend anymore, differently than in 2009 , is still current in many fields. In areas related to Medicine, it has been particularly popular; however, it is still classically developing in fields connected with Engineering, Computer Science, and Environmental Science.

Consequently, it should be interesting to investigate how the number of publications related to quality management has formed in certain areas. The map of the connections between areas, made with the help of the VOSviewer program, is presented in Figure 6.

The map of the connections between the areas, in which the articles, conference papers, books or book chapters related to quality management were pub-
Tab. 1. Clusters of areas connected with publications related to the scope of quality management in 1991-2016

\begin{tabular}{|l|ll|}
\hline CLUSTERS & & \\
\hline Cluster 1 & - & Environmental Science \\
& - & Agricultural and Biological Sciences \\
& - & Biochemistry, Genetics and Molecular Biology \\
& - & Earth and Planetary Sciences \\
& - & Pharmacology, Toxicology and Pharmaceutics \\
& - & Chemistry \\
& - & Chemical Engineering \\
& - & Energy \\
& - & Immunology and Microbiology \\
\hline Cluster 2 & - & Veterinary \\
& - & Medicine \\
& - & Sursing \\
& - & Hecial Sciences \\
& - & Psychology \\
& - & Arts and Humanities \\
& - & Neuroscience \\
& - & Dentistry \\
\hline Cluster 4 & - & Engineering \\
& - & Computer Science \\
& - & Material Science \\
& - & Mathematics \\
\hline Cluster 3 & Pecision Science \\
& - & Economics, Econometrics and Finance \\
\hline
\end{tabular}

Source: author's elaboration based on (https://bazy.pb.edu.pl, 27.11.2016). 


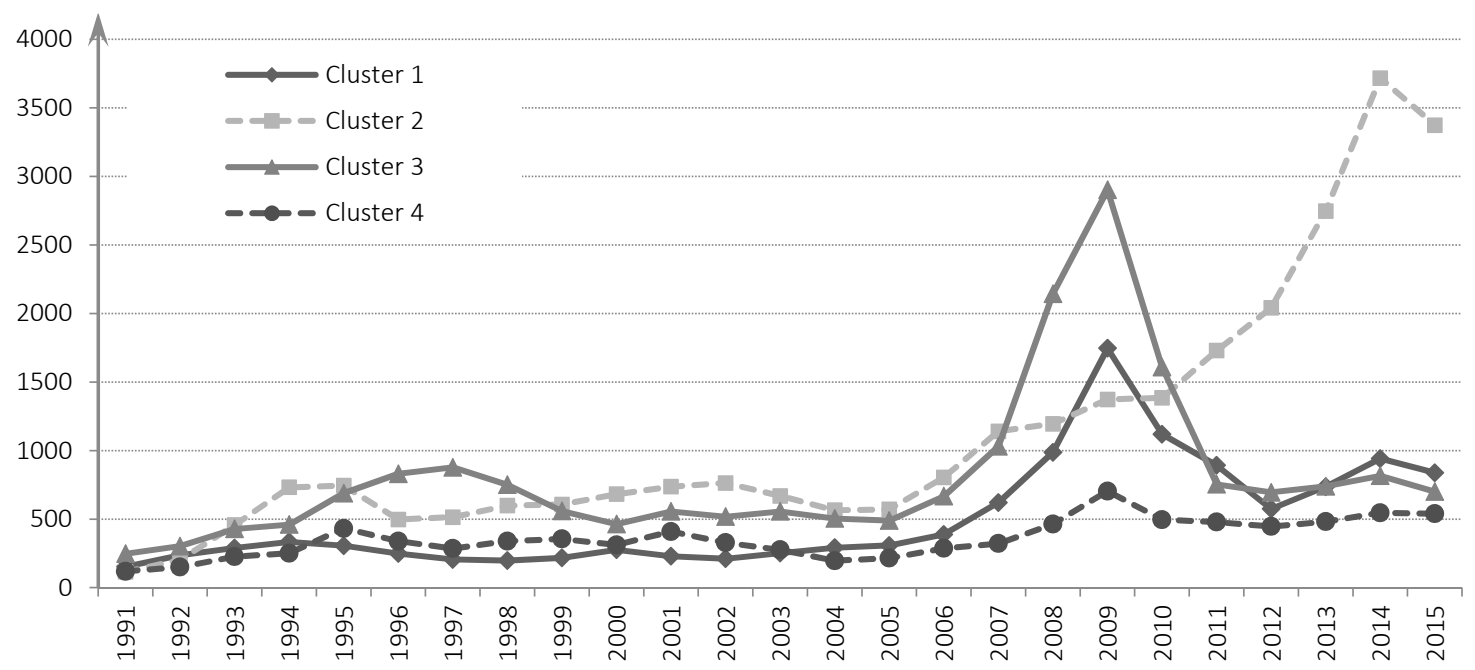

Fig. 7. Number of publications connected with the notion "Quality Management" from the database Scopus grouped into clusters Source: author's elaboration based on (https://bazy.pb.edu.pl, 27.11.2016).

lished is presented in Figure 6. It indicates the existence of many links between the fields. The strongest connections are between areas, such as Engineering, Computer Science, the area of Business, Management and Accounting and Decision Science, but also between Medicine, Nursing and Social Science.

The construction of the dependents map also allows to point out the clusters of areas appearing most frequently in publications related to quality management. The compartmentalisation into clusters can be observed in Figure 6 (highlighted in different colours) as well as in Table 1.

The analysis of the co-existence of areas, in which issues of quality management have been discussed, indicated the presence of four clusters. The first of them involved fields such as Environmental Science, Agricultural and Biological Sciences, Biochemistry, Genetics and Molecular Biology as well as many others. The second cluster concerned mainly the areas of Medicine, Nursing, Social Sciences, and Health Professions. The third one referred primarily to the areas of Engineering, Computer Science Material Science, and Mathematics. Finally, the last cluster included the fields of Business, Management and Accounting, Decision Science and Economics, Econometrics and Finance.

The resulting division will serve as the basis for further analysis of changes in the number of publications related to quality management during the considered period. Figure 7 presents the view of the number of publications per all clusters.

While analysing the changes of the total number of publications from areas of certain clusters, it should be mentioned that those related to quality defined in the context of the environment (Cluster 1) gained the highest amount in 2009. After that time, the interest in the described aspect has decreased and remained at a plateau over the last couple of years at about 800-900 publications per year. It should also be noted that this particular cluster has shown over a fivefold increase in the number of publications from the scope of quality management during the considered period, which gives us an average growth rate of about $7 \%$ per year. A similar situation took place in the case of Cluster 3, which relates to Engineering in the broad sense. However, while analysing the course of changes in the number of publications from this cluster, two temporal increases should be underlined. The first occurred in 1995-1998 (the result of the increase in the number of publications in the area of Material Science), and the second - in 2007-2010, which was related to a peculiar trend of quality management. Since 2011, the number of publications in this cluster has reached a plateau of about $700-800$ publications per year. Considering the classical association of quality management with engineering and related areas (e.g. Material Science, Computer Science), this cluster had the highest number of publications in comparison with other clusters from the beginning of the considered period, and that is also the reason behind the lowest increase. It was nearly threefold, which gives an average growth rate of about $4 \%$ per year. Over a fourfold increase in the number of publications was observed in the case of Cluster 4, which involves issues of quality management connected with Management and Economy. The average growth rate, in this case, was over $6 \%$ per year. The number of this type of publications seemed to be nearly systematically and con- 
stantly increasing, with temporary accelerations (e.g. in 2009). The highest - almost a thirtyfold - increase in the number of publications related to quality management was noticed in Cluster 2, which is connected with the fields of Medicine and Human Health. During the considered period, this cluster gained the average growth rate of $15 \%$ per year. aspects of the healing process. The second cluster (green colour) is also connected with Medicine, but this time, in the context of quality of the organisation of work in the hospital and attitudes promoted among employees. The last third group of publications was related to the classically understood company quality management, which contains mainly the terms

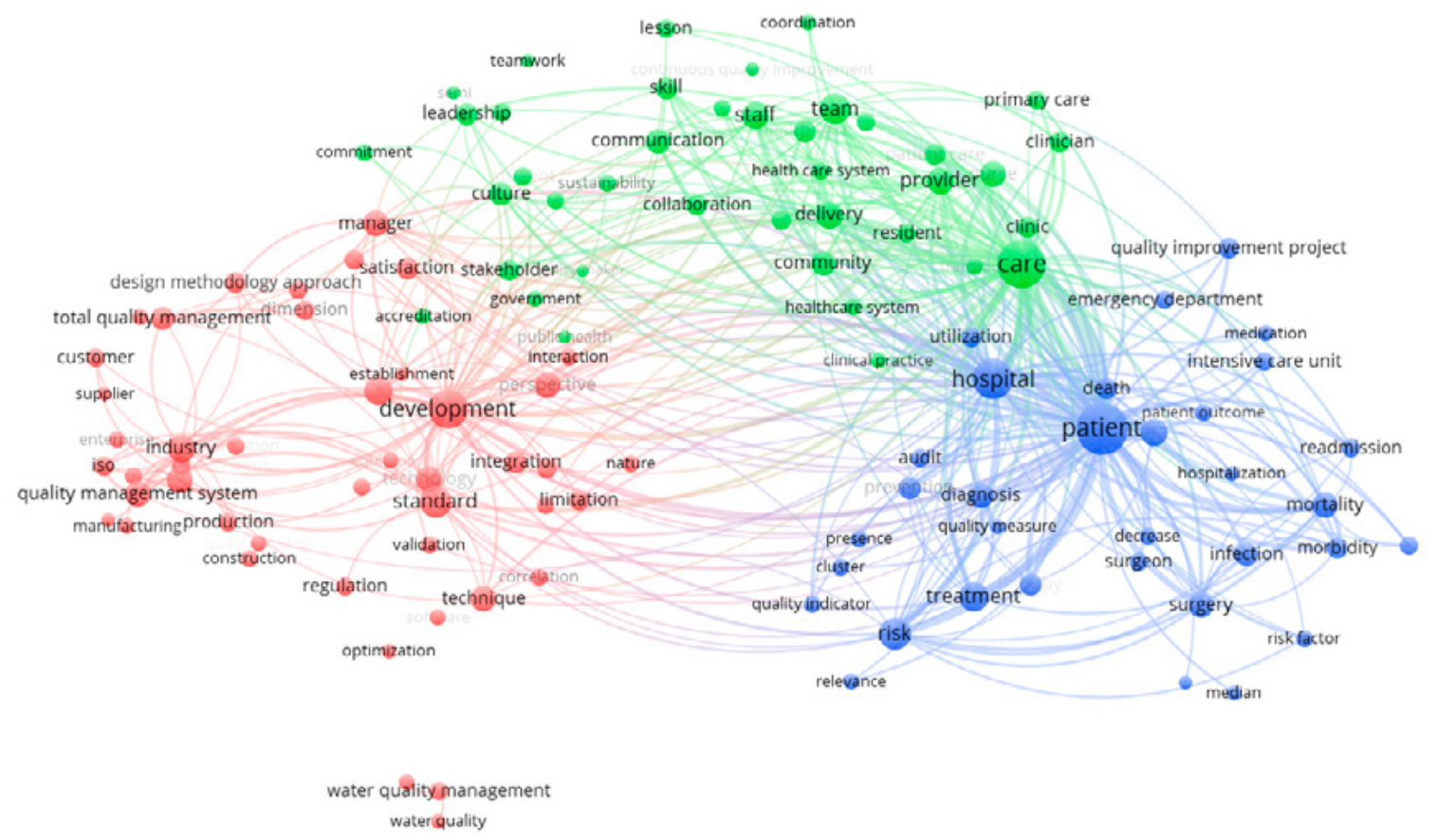

Fig. 8. Map representing the co-occurrence of terms characterising analysed articles related to the scope of quality management in 2014 Source: author's elaboration based on (https://bazy.pb.edu.pl, 27.11.2016).

\section{ENHANCED ANALYSIS}

The next step of conducting the analysis was a process of making maps representing the co-existence of issues covered together with quality management over the last two years and partly 2016.The analysed material also included titles, summaries, and keywords found in the database Scopus. The resulting dataset was reduced by choosing only those terms that appeared for at least 40 times and by eliminating expressions characteristic for every publication, such as purpose, trends, theory, and scope. The created map of the year 2014 is presented in Figure 8.

Figure 8 highlights three primary groups of terms, which have appeared in publications related to quality management. The first cluster (blue colour) contains terms related to the process of treatment, including, for example, opinions of patients, evaluation of their stay in the hospital, qualities of different related to the production process. It includes expressions connected to standards, development, the perspective of a client and supplier, product design or innovations. This group also contains classified elements related to quality in the context of Environment (water quality).

The next co-occurrence map was created using the data of 2015 (Fig. 9). It also indicates the existence of three groups of publications related to the term "quality management". One of them, similarly to this in 2014, was created using the publications connecting that term with Healthcare and related risks. The next group included expressions related to the quality of actions undertaken in hospitals. They cover, for example, actions linked with education and training for personnel as well as team management. There also appeared aspects connected with documentation and equipment used. The last cluster referred to publications related to quality management in the case of different companies. However, in that year, they were 


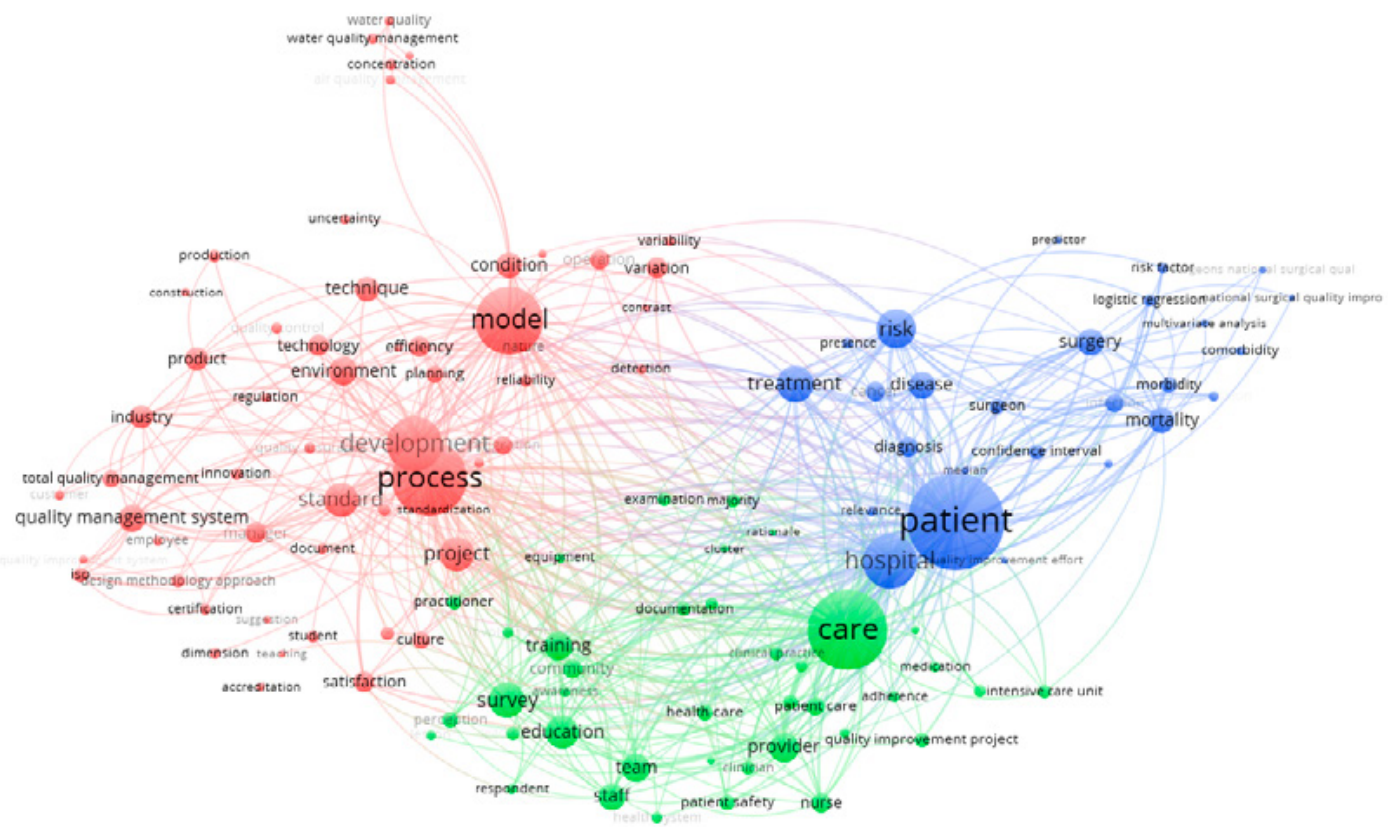

Fig. 9. Map representing the co-occurrence of terms characterising the analysed articles related to the scope of quality management in 2015

Source: author's elaboration based on (https://bazy.pb.edu.pl, 27.11.2016).

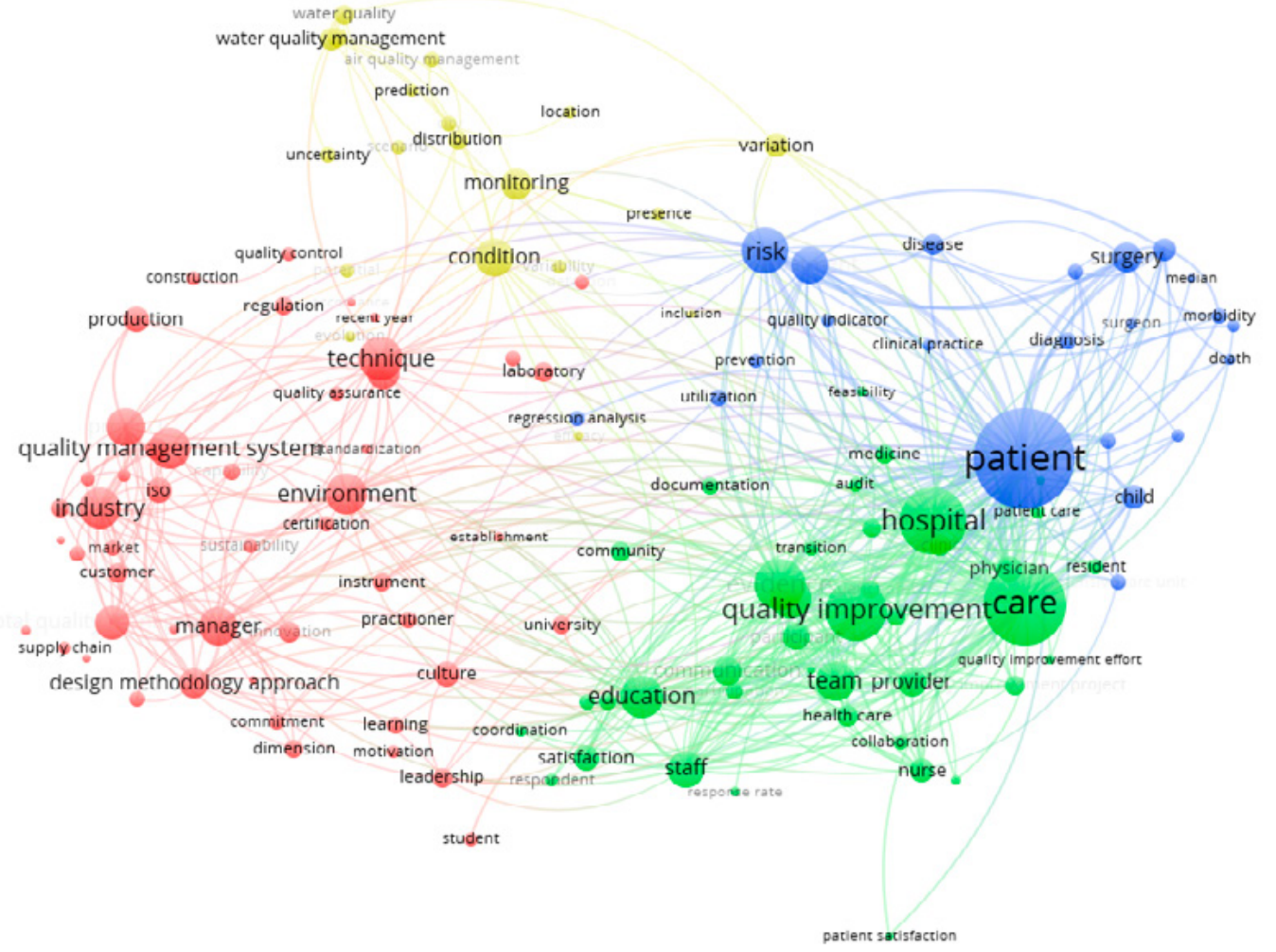

Fig. 10. Map presenting the co-occurrence of terms characterising analysed articles related to the scope of quality management in 2016

Source: author's elaboration based on (https://bazy.pb.edu.pl, 27.11.2016). 
mainly combined with concepts of process, project or modelling. Apart from those, such expressions as development, planning, client satisfaction or standardisation were found.

Over the analysed part of 2016, there were much fewer publications than after the previous year, and that is why expressions were chosen that appeared at least 20 times. After, they were excluded if characteristic for all documents, just like in the previous years. The resulting map was presented in Figure 10. It demonstrates that publications related to quality management grouped into four clusters. The first one, similarly to two previous years, was concentrated on issues connected with Healthcare. The second one, also related to hospitals, included expressions referring to people management, with particular emphasis on their education or training, as well as communication. The next cluster covered quality management in the context of different companies, mainly production ones. The publications discussed issues related not only to quality management but also to the environment, standardisation or designing. Again, techniques and technology were widely described but, on the other hand, the organisational culture was another focus of attention. That year also saw one group of publications connected with issues of quality management linked to the protection of the environment (water and air).

\section{CONCLUSIONS}

Term "quality management" is a very broad concept. The above analysis indicates that for last 25 years, it has been developing in four different groups, described here as clusters, namely, (1) Environmental Science, Agricultural and Biological Sciences, Biochemistry, Genetics and Molecular Biology, and many more; (2) Medicine, Nursing, Social Sciences and Health Professions, etc.; (3) Engineering, Computer Science Material Science and Mathematics, and others; and (4) Business, Management and Accounting, Decision Science and Economics, and Econometrics and Finance. Changes in the number of publications in the clusters occurred differently; however, the analysis of their execution indicates the existence of certain publication trends. The issue of quality management for the most part (excluding Cluster 2) was the most popular in 2009. After that, the interest in the subject has significantly decreased. The exception was the cluster linked with Medicine.
The highest publication popularity occurred in 2014 . Overall, it is worth mentioning that despite some temporal drops, the number of publications related to quality management has significantly increased during the considered period. The increase ranged from several times (in the case of engineering cluster) to a few dozens (in the case of medicine cluster) of times.

Apart from dynamics, the issues covered by certain clusters have also changed. For example, the analysis of expressions co-existence maps presented above. Therefore, in the cluster related to Medicine, two trends were noted during the considered period. The first was connected only to the process of healing and therapy; however, the second one concerned healthcare service providers. Also, in the case of the second one, the increase in the importance and interest in education and training of employees was noticed over the considered years. The remaining three clusters, despite references to publications from the scope of Medicine (especially in the case of the second trend), were linked mainly to analyses and researches related to the functioning of companies. In this group, changes in trends were also noticeable. Therefore, for example, in 2014, the attention to the context of quality management was drawn to the development and integration, while widely describing expressions related to standardisation and different types of limitations. In the next year, more focus was given to the context of the development or standardisation, processes, projects, and models. Moreover, the year 2016 focused on techniques and technologies. On the other, more attention was given to culture, leadership, and improvement of employees.

In summary, it should be stated that the issue of quality management is not only an important problem from the science perspective but also a very dynamic subject which is continuously and intensively developed by many researchers.

\section{ACKNOWLEDGEMENTS}

The research was conducted within S/WZ/1/2014 project and was financed from Ministry of Science and Higher Education funds.

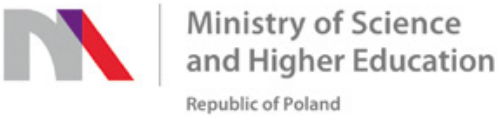


7th International Conference on Engineering, Project, and Production Management (EPPM2016) was financed in the framework of the contract no. 712/P-DUN/2016 by the Ministry of Science and Higher Education from the funds earmarked for the public understanding of science initiatives.

7th International Conference on Engineering, Project, and Production Management (EPPM2016) finansowana w ramach umowy 712/P-DUN/2016 ze środków Ministra Nauki i Szkolnictwa Wyższego przeznaczonych na działalność upowszechniającą naukę.

\section{LITERATURE}

Gudanowska, A. E. (2010). Wprowadzenie do zarządzania jakością w przedsiębiorstwie produkcyjnym [Introduction to quality management in a manufacturing company]. Ekonomia i Zarządzanie, 4(2), 161-170.

Urban, W. (2007). Definicje jakości usług - różnice oraz ich przyczyny [Definitions of service quality - differences and their reasons]. Problemy Jakości, 3, 4-9.

Elshennawy, A. K. (2004). Quality in the New Age and the Body of Knowledge for Quality Engineers. Total Quality Management, 15(5-6), 603-614.

Szczepańska, K. (2013). Doskonalenie zarządzania jakością: podstawy, ocena, perspektywa [Improvement of quality management: basis, evaluation, prospect]. Warszawa, Poland: Oficyna Wydawnicza Politechniki Warszawskiej.

Urban, W., \& Czerska, J. (2016). Reaching an entrepreneurial management system of amoebas. A qualitative insight into the European experience. Ekonomia i Zarzadzanie, 8(1), 7-18.

Liepiņa, R., Lapina, I., \& Mazais, J. (2013). Contemporary issues of quality management: relationship between conformity assessment and quality management. Contemporary Issues in Business, Management and Education. Procedia - Social and Behavioral Sciences, 110, 627-637.

Johnson, K. (2001). Philip B. Crosby's mark on quality. Quality Progress, 34(10), 25-30.

Standard ISO 9000 (2015). Quality management systems Fundamentals and vocabulary.

Gudanowska, A. E. (2015). Tworzenie mapy wiedzy opartej na tematyce projektów badawczo - rozwojowych na przykładzie województwa podlaskiego [Creating knowledge maps based on the themes of R\&D projects on the example of the Podlaskie region]. Ekonomia i Zarządzanie, 7(1), 257-270. 